\title{
Beyond Orientation: The Roles of Senior Librarians in Training Entry-Level Reference Colleagues
}

\section{Mary M. Nofsinger and Angela S. W. Lee}

\begin{abstract}
Little of the professional literature on the training process for newly hired reference librarians discusses the roles and impact of senior, more experienced colleagues in academic libraries. This paper explores the significant ways in which senior librarians contribute to the long-term educational, professional, collegial, and career development of entry-level reference librarians. The authors emphasize that senior librarians play vital roles by assisting junior colleagues in learning essential library skills and knowledge, by facilitating the assimilation of organizational and institutional values and norms, by serving as role models for effective interpersonal relationships, and by mentoring entry-level librarians in professional development activities.
\end{abstract}

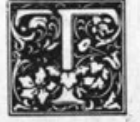

he old myth that reference librarians can perform effectively at the reference desk immediately after receipt of their M.L.S. degree has been widely disputed in library literature. ${ }^{1}$ Recent surveys by Ronald R. Powell and Karen Y. Stabler confirm that entry-level academic librarians frequently do not possess essential knowledge and proficiencies which are crucial for successful performance as reference librarians. ${ }^{2}$ These survey findings are supported by Ruth E. Bauner, who found that many newly hired academic librarians lack adequate knowledge of reference interview techniques, in-depth familiarity with general and specialized reference sources, knowledge of library policies and standard operating procedures, understanding of the philosophy of a particular library's reference department, and skills in using new technologies such as CD-ROMs, computerized systems, and online searching. ${ }^{3}$

\section{LITERATURE ON REFERENCE TRAINING}

Traditionally, heads of reference have been assigned most of the responsibility for teaching entry level reference librarians essential knowledge and proficiencies needed on the job after initial employment. Since the early 1980 s, books and journal articles in the library literature have clearly delineated these roles and responsibilities for heads of reference. ${ }^{4}$ However, the professional literature largely has neglected the important roles that senior, more experienced librarians play in the reference training process. This is not surprising since reference training expectations vary widely, depending on the needs and circumstances of a particular institution. 
Furthermore, Stabler's survey of recent library school graduates shows that the majority of academic library reference training programs in the United States are completed within a month. This a relatively short period of time, considering the quantity of knowledge and skills still to be learned and the high expectations of newly hired librarians. ${ }^{5}$ William F. Young theorizes that the most likely reason for this reliance on short reference training programs is the prohibitive expense in terms of personnel effort and time required for more extensive training. ${ }^{6}$ Additional factors may include the realities of modern day reference environments, such as stress and excessive workloads, and the necessity for heads of reference and other librarians to juggle additional duties and multiple roles simultaneously with training. ${ }^{7,8}$

\section{FOUR ROLES OF SENIOR LIBRARIANS}

Given the realities of contemporary academic library reference environments and the typically short training programs provided by many heads of reference, how can entry-level reference librarians continue to build their skills, knowledge, and other proficiencies after initial training? The authors postulate that more experienced reference librarians play significant, perhaps vital roles in the completion of successful reference training programs. Senior librarians have a unique opportunity to guide and inspire junior colleagues who may be intimidated by the hierarchy of the library and the parent institution while they struggle for competence and confidence in their first professional position. ${ }^{9}$ Supportive senior colleagues can explicitly share their skills, experience, attitudes, and enthusiasm with newly hired librarians, thereby fulfilling a variety of essential roles. Although many of these senior librarian roles overlap and complement each other, the authors have roughly separated them into four categories in order to discuss and emphasize their importance: (1) teacher/coach; (2) interpreter/adviser for organizational and institutional cultures; (3) interpersonal role model; and (4) mentor for professional development.

\section{The Teacher/Coach Role}

When faced with gaps in knowledge regarding reference resources, techniques, or skills, entry-level librarians frequently find that their best source may be other, more experienced librarians. ${ }^{10}$ Although newly hired librarians may have acquired basic knowledge of reference resources through graduate education or through other positions, there is a vast array of specialized literature in a large academic library reference department and much to learn which is specific to a particular position in a particular library. Instead of relying solely on "reference osmosis," the slow accumulation of knowledge and skills over time, junior librarians need to utilize the expertise of more experienced colleagues:

Much like an apprentice, the librarian must practice, refine, and develop his talents in all areas of librarianship. Studying specific reference tools, observing senior librarians as they conduct reference interviews, practicing search strategy on challenging questions, reviewing videotapes of instruction classes, and verifying difficult citations in various online systems are examples of ways in which these skills are honed."

The professional literature largely has neglected the important roles that senior, more experienced librarians play in the reference training process.

Thus, daily contact at the reference desk and discussion with more experienced reference librarians is an especially important aspect of learning on the job. Furthermore, Sheila Creth stresses the need to encourage newly hired librarians to accept coaching from other members of the library staff or in the profession because everyone involved benefits from a broad spectrum of views 
and opinions. ${ }^{12}$ However, there may be barriers to the coaching role; e.g., some librarians may be sensitive about asking questions which they do not feel capable of answering themselves. When such situations occur, entry-level librarians need to be proactive in consulting senior colleagues quickly in order to learn effective interpersonal skills and conflict management techniques.

\section{Instead of relying solely on \\ "reference osmosis," the slow accumulation of knowledge and skills over time, junior librarians need to utilize the expertise of more experienced colleagues.}

Since reference librarians must deal with questions in a vast range of subjects and in varying degrees of complexity, it behooves them to pool expertise since no one can fully master all subject areas in the realm of knowledge. An alternative approach involves "the idea of 'the shared question,' a query that can be fielded and answered by more than one librarian." ${ }^{13}$ This approach encourages newly hired librarians to develop open communication patterns with senior colleagues long before difficult queries arise. If that has been accomplished, junior librarians will then feel free to ask for help or to contribute assistance to a fellow librarian without worrying about stepping on one another's toes or "turf."

More formal approaches to utilizing the expertise and skills of other librarians have been developed at various libraries. Several peer coaching or "partnering" programs have been used successfully to improve the transfer of new skills learned to the work situation and to improve reference desk behaviors. ${ }^{14}$ Such programs usually include the voluntary choice of a coach (mutual agreement is mandatory), the identification of objectives to be accomplished (observable behaviors), observation of "coachee" by the coach, provision of descriptive feedback from coach to the "coachee," and provision of intermittent reinforcement so that positive reference desk behaviors are maintained:

The reported effects of the program were (1) greater clarification of the reference process for all staff involved in coaching; (2) increased recognition of positive communication behaviors, both through observation and feedback; (3) increased self-awareness of individual communication style and desk behavior; and (4) increased reinforcement of positive desk behaviors. ${ }^{15}$

In summary, utilizing the expertise of more experienced reference librarians as frequently as possible benefits not only the newly hired librarian, but probably also increases the skills and sensitivity of senior colleagues as well. Discussions of new perspectives and consideration of alternative ways of doing things might also increase esprit de corps within the reference department. Eventually, sharing information and consulting with colleagues could improve the overall quality of reference service provided to library users.

\section{The Interpreter/Adviser Role}

Senior librarians also play a significant role in helping entry-level librarians fully comprehend the unique climate and culture of their particular organization and institution. This culture includes numerous facets, such as:

- Policies, priorities, goals, and objectives for reference service

- Acceptable public service attitudes and behaviors

- Organizational values and norms

- Social, economic, and political context in which the library operates

Given the magnitude and complexity of an academic library, the diversity within individual units, and the changing objectives and priorities of library administrators, newly hired librarians may need an extended period of time to complete this assimilation process.

Policies, Priorities, Goals, and Objectives. Each reference department's policies, priorities, goals, and objectives for service should be communicated to newly hired librarians early in the training process: 
Is the reference department's mission to educate users or provide them answers? .... Does the department provide different levels of service for different classes of users? .... What is the minimum level of service that is professionally and institutionally appropriate?... How much time should reference librarians devote to handling individual questions? .... What types of questions are considered out of bounds and not to be answered?'16

What are the priorities for service when the librarian has several library users standing in front of the reference desk, another information request arrives via the telephone, and there is a backlog of additional questions requiring extensive research?

Is the primary objective one of service? ... . Is the primary objective the production of research and publications for the enrichment of the professional family and to further the standing of the library within the national academic community? Perhaps the primary objective is concentration on the materials of the library? ... Or is the primary objective, at least for the next year or two, educafing staff in the new technologies? ${ }^{17}$

\section{What are the priorifies for service when the librarian hasseveral Iibrary users standing in front of the reference desk, another information request arrives via the telephone, and there is a backlog of additional questions requiring extensive research?}

More experienced librarians, by virtue of their experiences in having "learned the ropes," can help junior colleagues answer these and other questions within the context of each department's unique service environment. They can also ask hard questions about establishing, achieving, and reviewing individual performance goals, such as: Are those realistic goals? What are your primary objectives? Have otheralternatives been considered? Is there enough time to work on all goals simultaneously? Which activities can be dropped to make time for priority tasks? In this manner, senior colleagues can assist junior librarians with integrating their individual priorities, goals, and objectives with those of the reference department and the library.

As part of becoming familiar with professional goals and objectives, senior librarians may also ask their junior colleagues to read and then discuss RASD's "Information Services for Information Consumers: Guidelines for Providers." 18 These guidelines present a national perspective on goals for both librarians and users in the areas of information services provided, allocation of resources, access to information and resources, library staffing, and the rationale for evaluation of services. Understanding and assimilating these professional guidelines will also help junior colleagues become more aware of the importance of improving public service.

Service Attitudes and Behaviors. Although there is no ideal combination of personality traits that all senior librarians consistently display when providing quality reference service, attitudes and behaviors strongly influence library users' perceptions in a positive or negative manner. "Perhaps no characteristic of academic reference librarians draws more praise from student users than all around approachability," which includes basic things like smiling, making direct eye contact, standing up as someone approaches the reference desk, listening attentively, displaying a positive attitude, and then asking open-ended or neutral questions to clarify needs. ${ }^{19}$ When users appear to need assistance, reference librarians should be proactive and initiate appropriate behavior, such as asking, "Have you found everything you need?"

Additional interpersonal traits and behaviors which are invaluable when providing reference service are tenacity, courtesy, and communication skills. Tenacity refers to the ability to pursue a question tactfully until an answer is found, even if this requires gentle 
probing for more information from the user. As for courtesy, both colleagues and users should be treated with professional respect and patience. Often this involves using common sense, considering others' needs, and doing one's fair share of the work. Entry-level librarians also need to learn appropriate communication skills by observing and participating in interactions with senior colleagues, by talking through ideas in different contexts, and by receiving feedback on their ability to listen, explain, articulate, question, and establish rapport with users.

Senior librarians should also discuss professional ethics during the training of newly hired librarians, who must become knowledgeable about ethical concepts and related policies contained in The Library Bill of Rights and the ALA's Statement on Professional Ethics. ${ }^{20} \mathrm{Al}-$ though many junior librarians are already familiar with the doctrine of confidentiality of library records, patron files, and circulation records,

the most intractable ethical dilemmas arise when the duty to provide unbiased service conflicts with our personal or institutional biases, values, or priorities. This is thus the most complex area of reference ethics, as our interactions with both clients and the collection present a wide range of opportunities for conscious or unconscious conflicts. ${ }^{21}$

Other issues which require the reference librarian to use discretion and mature judgment include those situations which involve restrictions on access to certain materials, censorship in the selection of materials, equality of service, and free-versus-fee services. Ideally, experienced librarians would serve as consultants for junior colleagues when difficult ethical situations arise.

Organizational Values and Norms. Newly hired librarians can usually assimilate written guidelines and rules, but they frequently have difficulty grasping the intangible (unwritten) nuances of a particular library's values and norms:

Values .... are subjective, preferred states that guide action choices and become observable or identifiable through behavior. These beliefs ... clarify what individuals are supposed to do and reward them for doing it well ... Norms are the unwritten rules of group behavior (the informal structure) that are initiated and maintained by collective human behavior. These are influenced initially by the expectations, attitudes, and assumptions that members bring to a group. ${ }^{2}$

\section{Other issues which require the reference librarian to use discretion and mature judgment include those situations which involve restrictions on access to certain materials, censorship in the selection of materials, equality of service, and free-versus-fee services.}

Senior librarians can help junior colleagues assimilate a particular library's values and norms for behavior more rapidly and accurately than would be possible by learning through trial and error. When a newly hired librarian arrives fifteen minutes late at the reference desk, thereby embarrassing a senior colleague who has a very important campus meeting, concise verbal feedback usually suffices to immediately inculcate the norms of prompt arrival for scheduled shifts, respect for colleagues' needs, and the importance of reliability.

Other academic reference librarian norms which are highly regarded include cooperation, honesty, sharing of information, acceptance of responsibility, accuracy, people-oriented service, and courtesy. Even though formal written rules may not exist, a courteous librarian will display some of the following attributes and behaviors:

- Kind, thoughtful, considerate to all patrons.

- Attentive to patrons's requests and comments.

- Responsive, takes action immediately.

- Patient with those who need assistance, instruction.

- Tactful in difficult situations. 
- Friendly, cheerful disposition that is ... natural, not forced or fake, concerned about patrons' needs and complaints, sympathetic with patrons' difficulties in finding information. ${ }^{23}$

After successfully assimilating organizational values and norms, entry-level librarians will then be able to function in more appropriate ways and will be more productive in their work. They will also have a clearer sense of direction and can focus their energies toward types of performance which will be rewarded. Newly hired librarians who clearly understand their library's values and norms will also be better able to explain public service policies and procedures to library users.

The Librarian's Role in the Institutional Culture. In a wider context, newly hired librarians must become familiar with the social, economic, and political context in which an academic library operates. Professor Edward G. Holey writes:

An understanding of the broader picture of higher education would help us [librarians] formulate strategies for achieving our goals.... Anyone who believes that multi-million-dollar operations [academic libraries] can function without involvement in the political process or an understanding of fairly well-defined structures that reflect basic academic values is surely living in a dream world. ${ }^{24}$

Senior librarians must assist junior colleagues to better understand the context in which an academic library functions. They can stress that, in addition to performing primary responsibilities within the library, the role of librarians includes supporting the university, its mission, and its institutional goals and values. Experienced colleagues can introduce newly hired librarians to faculty in relevant campus departments and share effective techniques for developing strong working relationships with teaching and research faculty. They can also encourage appropriate participation in university committees and governing bodies as well demonstrate how to participate in activities with citi- zens in the local community and within the state.

Professor Holey also stresses that academic librarians must develop an appreciation for the history of scholarship and learning, a better understanding of how knowledge is obtained in various disciplines, and the ability to evaluate research findings. ${ }^{25}$ Many librarians obtain this appreciation for scholarship and learning by performing research and scholarly activities in addition to other primary responsibilities. The" "publish-orperish" syndrome must be taken seriously by academic librarians who wish to become tenured and/or promoted. Experienced senior librarians thus serve as valuable sources of information for junior colleagues who often doubt their ability to meet these institutional realities.

Experienced colleagues can introduce newly hired librarians to faculty in relevant campus departments and share effective techniques for developing strong working relationships with teaching and research faculty.

In summary, newly hired librarians go through an academic library socialization process as they adapt to their organization's unique culture with its norms for acceptable and unacceptable behavior patterns. Throughout this socialization process, senior librarians should be alert for opportunities to help junior colleagues understand both the organizational and institutional cultures. Furthermore, more experienced colleagues must serve as guides for entry-level librarians learning how to successfully function as members of the broader academic community.

\section{The Interpersonal Role Model}

Whether they like it or not, senior librarians involuntarily serve as interpersonal role models because of the old adage, "Actions speak louder than words." Frequently junior librarians instinctively choose a senior colleague as a 
role model because they recognize the value of depth of knowledge and extensive experience. ${ }^{26}$ In order to integrate newcomers easily and quickly into the reference department, an informal "buddy system" should be encouraged. When this happens, a senior librarian volunteers to be available during work hours for a junior colleague to contact for counsel and assistance. If their personalities and interests are compatible, then the buddy system is successful. If they are incompatible, then the newcomer eventually turns to another senior librarian as a role model.

\section{Working at a reference desk can be stressful, especially for entry-level librarians who may lack experience dealing with demanding patrons, the hectic pace of business, the reference interview, and their own incomplete knowledge of reference sources.}

Another valuable function fulfilled by senior librarians is that of role model for cooperation among professional colleagues. As mentioned earlier, reference departments have unique values and norms, and collegiality and cooperation are usually highly valued traits:

The cooperation and collegiality that can be part of reference service brings joy to reference librarians fortunate enough to work in such an environment.... Collegiality contributes to building a positive daily environment, sharing responsibility for completion of special projects, and fostering professional and personal growth. ${ }^{27}$

Since interpersonal relationships within a department are not always congenial, a senior colleague can also provide sage advice and a mature perspective when needed. Newcomers may also observe how experienced colleagues balance individual needs for independence while working closely with the reference team.

More experienced colleagues are also crucially important for modeling good interpersonal skills in one-on-one interactions with library users. Working at a reference desk can be stressful, especially for entry-level librarians who may lack experience dealing with demanding patrons, the hectic pace of business, the reference interview, and their own incomplete knowledge of reference sources. The ability to work well under pressure can be facilitated through teamwork:

Strong and supportive colleague relationships among a reference team may be the ... most effective defense against dysfunctional coping strategies. ... Reference librarians need to exchange viewpoints with their peers, and to discuss with them their frustrations, disappointments, and feelings of resentment toward patrons. ${ }^{28}$

In addition, senior colleagues often model how they cope with physical tiredness, mental exhaustion, multiple or conflicting demands, and other routine byproducts of reference work. Thus, it is also essential that senior librarians occasionally take time to give both themselves and their junior colleagues a well-deserved pat on the back.

\section{The Mentor Role in Professional Development}

As in any profession, growth and development in librarianship should be part of a continual, lifelong learning process. Entry-level librarians often find that library administrators are highly supportive of professional growth activities in principle, but they sometimes lack sufficient financial resources or adequately trained personnel necessary to establish extensive faculty development programs. Despite these and other constraints, library administrators often provide support for professional development activities through personnel policies or practices such as released time for research, dual job assignments, workshops, job sharing, sabbaticals, management internships, special project leaves, retraining, staff exchanges, and similar developmental activities. In addition, numerous senior librarians usually support the philosophy that professional growth and development activities:

strengthen a librarian's knowledge and abilities; contribute to the effectiveness 
of an individual's performance and to the achievement of personal and professional goals; are vital to .... a quality academic environment which depends on intellectually active librarians; are essential to the provision of quality library service; are supportive of the library's role on campus; are a shared responsibility between an individual . ... and the university providing appropriate time and resources; stimulate librarians to challenge themselves. ${ }^{29}$

\section{Within the library, mentors can assist newcomers in choosing among committee and task force activities wisely.}

Given the compelling reasons listed above for supporting professional growth activities, how can senior librarians effectively assist entry-level librarians in getting involved in meaningful ways? In addition to sharing accumulated knowledge with colleagues as mentioned earlier, senior librarians frequently assume the role of mentor for newly hired librarians:

Mentoring is a relationship between a person enjoying perceived power and a person aspiring to a position of power. This relationship exists within the political environment of the workplace.... The success of the mentoring relationship is fundamentally rooted in the concept of empowerment: the nurturing of competence (attitudes, knowledge and skills) in others. ${ }^{30}$

Why would entry-level librarians seek a mentoring relationship? Newcomers to librarianship may be intimidated by the bureaucracy of the library and the academic institution where they are struggling to develop competence and confidence in their first professional position. Also, entry-level librarians may be grappling with the concept of holding a job versus developing a career and struggling with pitfalls that ensnare librarians on the path toward tenure and promotion.

Many mentoring relationships are casual and informal. Senior librarians al- ready involved in library associations might provide advice on which memberships are most rewarding professionally, recommend newly hired librarians for committee service or conference activities, and introduce them to prominent people at professional meetings. Within the library, mentors can assist newcomers in choosing among committee and task force activities wisely. Mentors frequently discuss criteria and guidelines for tenure and promotion, and share information with new colleagues regarding annual review expectations and procedures. Mentors also make suggestions about research directions, grant applications, poster session topics, or mention possible service opportunities. Mentors can also work with colleagues in the research and publication process, thereby facilitating their scholarly development. In addition:

A mentor can ... provide guidance and assistance in the development of professional or managerial skills. A climate of creativity can be created by a developer of talent. The opener of doors [a mentor] can boost a protégé's introduction to organizational activities through use of the mentor's existing network. A mentor can provide the opportunity for involvement in challenging tasks.... A protector can rescue a protégé from mistakes and provide support when taking risks leads to failure. ${ }^{31}$

Other mentoring relationships are more structured and formal. At the University of Georgia, an experimental mentoring program was successfully tested in 1985, revealing that the opportunity to observe and interact with successful managers was very beneficial for entrylevel librarians. ${ }^{32}$ At the University of New Mexico, a Faculty Sponsor Program allows the selection of a senior librarian who serves as a mentor for each newly hired librarian. The mentor's responsibilities include serving as a counselor, assisting the newcomer in adjusting to the new environment, making introductions, arranging for orientation, guiding professional development, helping prepare for faculty reviews, and participating in a six-month review process for the 
junior colleague. ${ }^{33}$ These mentoring activities appear to offer many benefits.

\section{CONCLUSION}

Throughout this paper, the authors have noted how much senior librarians contribute to the learning process of junior librarians. In doing so, the authors have emphasized that more experienced librarians must become more aware that they play vital roles which assist entry-level librarians in making an effective and timely transition to an academic profession. When junior colleagues receive assistance from experienced librarians, they learn valua- ble skills, knowledge, attitudes, and behaviors which improve the quality of reference service provided to users. In addition, tenure and publication track activities appear less fearsome, working relationships appear more positive, and professional development and personal growth are enhanced. Senior librarians also experience satisfaction and pleasure in seeing entry-level librarians make further contributions to librarianship. Eventually, both the library organization and the profession benefit from successful collegial training relationships which assist and promote tomorrow's leaders.

\section{REFERENCES AND NOTES}

1. Among many sources: Virginia Massey-Burzio, "Education and Experience: Or, the M.L.S. Is Not Enough," RSR: Reference Services Review 19 (Spring 1991): 72-74;/Anne F. Roberts, "Myth: Reference Librarians Can Perform at the Reference Desk Immediately upon Receipt of M.L.S. Reality: They Need Training Like Other Professionals," in Academic Libraries: Myths and Realities (Chicago: Association of College \& Research Libraries, 1984), 400-404, Lois Walker, "All I Really Needed to Know I Didn't Learn in Library School," North Carolina Libraries 48 (Winter 1990): 258-59.

2. In Ronald R. Powell's article, "Sources of Professional Knowledge for Academic Librarians," College \& Research Libraries 49 (July 1988): 332-40, recent library science graduates acknowledged that almost 29 percent of their knowledge and skills was learned in school while about 35 percent was learned on-the-job;/Karen Y. Stabler, "Introductory Training of Academic Reference Librarians: A Survey," RQ 26 (Spring 1987): 363-69.

3. Ruth E. Bauner, "Reference Ready beyond the M.L.S.," in Continuing Education of Reference Librarians, ed. Bill Katz (New York: Haworth, 1990), 45-58. Also published in Reference Librarian 30 (1990).

4. Some of the better sources examined: Anne May Berwind, "Orientation for the Reference Desk," RSR: Reference Services Review 19 (Fall 1991): 51-54. seventeen articles in Reference Services Administration and Management, ed. Bill Katz and Ruth A. Fraley (New York: Haworth, 1982). Also published as The Reference Librarian, no. 3, (1982), Tara Lynn Fulton, "Mentor Meets Telemachus: The Role of the Department Head in Orienting and Inducting the Beginning Reference Librarian," in Continuing Education of Reference Librarians, ed. Bill Katz (New York: Haworth, 1990), 257-73. Also published in Reference Librarian, no. 30 (1990).

5. Stabler, "Introductory Training," 367-68.

6. William F. Young, "Communicating with the New Reference Librarian: The Teaching Process," in Reference Services Today: From Interview to Burnout, ed. Bill Katz and Ruth A. Fraley (New York: Haworth, 1987), 223-31. Also published in Reference Librarian, no. 16 (1986).

7. William Miller, "What's Wrong with Reference: Coping with Success and Failure at the Reference Desk," American Libraries 15 (May 1984): 303-306.

8. Barbara E. Kemp, "Multiple Roles of Academic Reference Librarians: Problems of Education and Training," in Personnel Issues in Reference Services, ed. Bill Katz and Ruth A. Fraley (New York: Haworth, 1986), 141-49. Also published in Reference Librarian, no. 14 (1986).

9. Jennifer Cargill, "Developing Library Leaders: The Role of Mentorship," Library Administration and Management 3 (Winter 1989): 12. 
10. Diana M. Thomas, Ann T. Hinckley, and Elizabeth R. Eisenbach, The Effective Reference Librarian (San Diego, Calif.: Academic Press, 1981), 167.

11. Fulton, "Mentor Meets Telemachus," 262-63.

12. Sheila D. Creth, Effective On-the-Job Training: Developing Library Human Resources (Chicago: ALA, 1986), 86-87.

13. Paul Frantz, "Expanding the Repertoire of Reference," RSR: Reference Services Review 19 (Winter 1991):88.

14. Two examples: Gwen Arthur, "Peer Coaching in a University Reference Department," College \& Research Libraries 51 (July 1990): 367-73, Ralph Gers and Lillie J. Seward, "I Heard You Say' ... Peer Coaching for More Effective Reference Service," in Information Brokers and Reference Services, ed. Robin Kinder and Bill Katz (New York: Haworth, 1988), 245-59. Also published in The Reference Librarian, no. 22 (1988).

15. Arthur, "Peer Coaching," 372.

16. Christopher W. Nolan, "Closing the Reference Interview: Implications for Policy and Practice," RQ 31 (Summer 1992): 519.

17. Dorothy E. Jones, "'I'd Like You to Meet Our New Librarian': The Initiation and Integration of the Newly Appointed Librarian," Journal of Academic Librarianship 14, (Sept. 1988): 223.

18. "Information Services for Information Consumers: Guidelines for Providers," $R Q 30$ (Winter 1990): 262-65.

19. Mary Ellen Collins, "Continuing Education for ARL Librarians in Multi-Faceted Public Service Positions," in Continuing Education for Reference Librarians, ed. Bill Katz (New York: Haworth, 1990), 25. Also published in Reference Librarian, no. 30 (1990).

20. American Library Association, "ALA Policy Manual," ALA Handbook of Organization (Chicago: ALA, 1991), 152, 154-55.

21. Gregory E. Koster, "Ethics in Reference Service: Codes, Case Studies, or Values?," RSR: Reference Services Review 20 (Spring 1992): 72.

22. Arthur C. Beck and Ellis D. Hillmar, Positive Management Practices (San Francisco: Jossey-Bass, 1986), 19, 131.

23. Catherine Suyak Alloway, "The Courteous Librarian: Helping Public Service Employees to Keep Smiling," in Reference Services Today: From Interview to Burnout, ed. Bill Katz (New York: Haworth, 1986), 287. Also published in The Reference Librarian, no. 16 (1986).

24. Edward G. Holley, "Defining the Academic Librarian," College \& Research Libraries 46 (Nov. 1985): 464.

25. Ibid, 464-66.

26. Creth, Effective On-the-Job Training, 87.

27. Polly Frank, Lee-Allison Levene, and Kathy Piehl, "Reference Collegiality: One Library's Experience," in Opportunities for Reference Services: The Bright Side of Reference Services in the 1990s, ed. Bill Katz (New York: Haworth, 1991), 35. Also published in Reference Librarian, no. 33 (1991).

28. Charles A. Bunge, "Potential and Reality at the Reference Desk: Reflections on a 'Return to the Field,'" Journal of Academic Librarianship 10 (July 1984): 131.

29. Ilene F. Rockman, "Promoting Professional Development: A Local Approach," College \& Research Libraries News 50 (Nov. 1989): 903.

30. Darlene Weingand, President's Program/Junior Members Round Table (Program handout at the American Library Association Conference, Dallas, Texas, 1989.

31. Jennifer Cargill, "Developing Library Leaders," 12.

32. Deanna L. Roberts, "Mentoring in the Academic Library," College \& Research Libraries News 47 (Feb. 1986): 117-19.

33. Joanne Colley and Connie Capers Thorson, "Mentoring along the Tenure Track," College \& Research Libraries News 51 (Apr. 1990) 297-300. 